\title{
Optimization of Multiple Performance Characteristics of Friction Stir Welded Joint with Grey Relational Analysis
}

\author{
Shanavas Shamsudeen ${ }^{*}{ }^{\mathbb{B}}$, John Edwin Raja Dhas ${ }^{b}$ (당 \\ ${ }^{a}$ Department of Mechanical Engineering, Noorul Islam University, Tamil Nadu, India. \\ ${ }^{b}$ Department of Automobile Engineering, Noorul Islam University, Tamil Nadu, India.
}

Received: November 29, 2017; Revised: July 28, 2018; Accepted: September 28, 2018

\begin{abstract}
In the present work, multi-objective optimization of the input welding parameters influencing the quality of weld joint of AA $5052 \mathrm{H} 32$ aluminium alloy by FSW process is investigated using response surface methodology and grey relational analysis. The quality of the welded joint is measured based on the higher value of tensile strength and hardness of the joint obtained by experimentation. A central composite design technique consists of 31 sets of experiments using four factors and five levels are used. Tool pin profile, rotational speed, welding speed, and tool tilt angle are selected as the significant input parameters. Analysis of variance (ANOVA) is used to analyze the effect of each input welding parameters on the output responses. Statistical results show that the developed regression model is adequate. Optimum levels of welding parameters are finally identified using grey relation grade. Grain structure of the welded joint is examined by observing the micro and macro structures of the weld.
\end{abstract}

Keywords: Aluminum Alloy 5052, Friction Stir Welding, Response Surface Method, Tensile Strength, Microstructure, Grey relational analysis.

\section{Introduction}

Aluminium and aluminium alloys are not easily weldable by fusion welding processes due to hot cracking, hydrogen embrittlement, distortion, and high residual stress ${ }^{1}$. The problem experienced by the fusion welding was resolved by the invention of a solid-state welding process named friction stir welding (FSW). It was first introduced by The Welding Institute (TWI) in 1991 and it is appraised to be a significant evolution in welding process due to better mechanical properties and environmental aspects ${ }^{2}$. Hence, this solidstate welding process attracted aerospace, automobile, and marine industries. In FSW, a non-consumable tool with a pin and a shoulder plunge into the abutting edges of the plates to be joined to a preset depth and translate along the joining line. During FSW, the material gets heated to a temperature much below the melting point of the metal; however, a change in microstructure occurs in and around the weld site. AA $5052 \mathrm{H} 32$ aluminium alloy is a strain-hardened Al-Mg alloy and it has high specific strength, high fatigue strength, workability, formability, good weldability, and very good corrosion resistance to seawater ${ }^{3,4}$. This justifies its use in aircraft structures, fuel tanks, marine structures, marine parts, food equipment, other transportation areas, sheet metal work, rivets, etc. ${ }^{5}$.

Significant input parameters such as tool pin profile, rotational speed, welding speed, tool tilt angle, etc. are responsible for weld quality ${ }^{6-25}$. Tool geometry is a very critical factor for the success of the FSW process. Tool pin profile governs the generation of the heat and stirring

*e-mail: shanavas.in@gmail.com required to join the material effectively. Extensive work on the influence of pin geometry on weld quality of aluminium alloys by FSW has been carried out on $2 \mathrm{xxx}, 6 \mathrm{xxx}$, and $7 \mathrm{xxx}$ aluminium alloy ${ }^{6-10}$. Bayazid et al. ${ }^{6}$ studied the effect of the pin profile on defects of FSW welds on AA 7075 aluminium alloy. Three different pin geometries, namely cylindrical, square, and triangular were used for the investigation. The result revealed that the joints made by square pin tool exhibited smaller grain size compared to that of other tools. Ugender et al. ${ }^{7}$ found that the tapered cylindrical pin profile exhibited superior tensile properties compared to straight cylindrical pin profile. The taper angle increased the contact area between the pin and workpiece and which increased the frictional heat.

Prasanna et al. ${ }^{8}$ studied the effect of hexagonal, square, tapered cylindrical, and triangular pin profiled tool on mechanical properties of FSW welded AA 6061 aluminium alloy. High carbon high chromium steel was chosen as tool material for the study. Venkateswarlu et al. ${ }^{9}$ developed a mathematical model to predict the effect of the tool geometries on the weld strength using response surface regression analysis. Different shoulder diameters, pin diameters, and levels of shoulder surface concavity were used for the investigation on AA 7039 FSW welds. The tool material used was stainless steel grade 310. Elangovan et al. ${ }^{10}$ used five different tool pin profiles namely straight cylindrical, tapered cylindrical, threaded cylindrical, triangular, and square to find the influence of tool pin profile on weld quality of AA $2219 \mathrm{Al}$ alloy welded by FSW. High carbon steel was used as tool material to fabricate the joint. Square pin profiled tool was suggested for sound welds in the mechanical and metallurgical aspects. 
A few studies were carried out on friction stir welding between AA 5052-O aluminium alloy plates ${ }^{11-12}$. Leonardo et al. ${ }^{13}$ studied the effect of tool shoulder diameter on heat input during FSW of AA 5052-H32 alloy. Ramachandran et al. ${ }^{14}$ studied the effect of tool rotational speed and tool tilt angle on the mechanical and metallographic characteristics of dissimilar friction stir butt joint between Al Alloy AA 5052-H32 and HSLA steel. Shanavas et al. ${ }^{15}$ carried out a comparative study between FSW and TIG welding performed on AA 5052-H32 Al alloy. The result revealed that the FSW was more versatile to weld AA 5052-H32 compared to conventional TIG welding.

Experimental design and analysis under a given set of operating parameters can be accurately and efficiently carried out by using the design of experiments (DOE). Response surface method (RSM) is such an experimental design and analysis method having more numbers of experimental runs and good interactions with variables. This overshoots the problem of few interactions with variables of Taguchi's method ${ }^{16}$. Therefore presently researchers prefer response surface design to design the experiments and analyze the welding parameters. Several works have been carried out on the RSM based design and analysis of FSW between aluminium alloy ${ }^{17-21}$.

Taguchi based Grey Relational Analysis (GRA) are widely used by researchers to solve a multi-response optimization problem. Kesharwani et al. ${ }^{22}$ presented a multi-objective optimization of welding parameters influencing the quality of FS welded joint of dissimilar AA 5052-H32 and AA 5754-H22. Tool rotational speed, translation speed, tool shoulder diameter, and tool pin geometry were considered as input parameters. Weld strength and percentage elongation were considered as output parameters. Taguchi grey based approach was used for optimization. Jitender et al. ${ }^{23}$ carried out FSW on AA 5083-H32 Al alloy for optimizing welding parameters. Taguchi grey based approach was used for optimization to maximize the responses such as ultimate tensile strength, elongation, and hardness. Tool rotational speed, transverse speed, and tool tilt angle were chosen as the significant input parameters for the study. Prakash et al. ${ }^{24}$ optimized the welding parameters for better quality of friction stir welded AM $20 \mathrm{Mg}$ alloy using Taguchi grey based approach. Tool rotational speed, welding speed, tool shoulder diameter, and plunging depth were considered as input parameters. Weld quality was measured based on the maximum value of responses such as tensile strength, elongation, and hardness.

Limited works were carried out on RSM based grey relational analysis to solve multi-response optimization problems. Vijayan et al. ${ }^{25}$ studied RSM based GRA approach to optimize process parameters for the FS welded AA 2024 and AA $6061 \mathrm{Al}$ alloy. Welding parameters such as tool rotational speed, welding speed, pin profile, and axial load were considered for the statistical experiment. Tensile strength and elongation were considered as the responses in the study. The welded joints are highly heterogeneous with weld nugget at the center, TMAZ, HAZ, and base metal on either side. So, when subject to tensile load the joints always fail at the weaker region. Hence the quality of the welded joint cannot be measured in terms of elongation of gauge length. Thus, even though some researchers considered elongation as a response for optimizing input welding parameters, in this work elongation is not considered for measuring the quality of joint. The quality of the weld is often decided by tensile strength and hardness. The traditional RSM approach is insufficient to solve a multi-response optimization problem. Optimizing the input parameters considering multiple responses need the aid of grey relation theory in addition to experimental design and analysis method. Therefore, RSM based grey relational analysis (GRA) is used in the present work. Hence in this paper, the input welding parameters influencing the multi responses such as ultimate tensile strength and hardness were optimized using a grey based RSM technique for FS welded AA 5052-H32 aluminium alloy joints.

\section{Experimental Setup}

Cold rolled aluminium magnesium alloy AA 5052-H32 plates of $100 \mathrm{~mm} \times 50 \mathrm{~mm} \times 6 \mathrm{~mm}$ were used to fabricate the butt joints. The chemical composition of the metal is presented in Table 1. Oxides on the surface of the plates were removed by wire brushing before welding. The direction of welding was parallel to the rolling direction of the plate. The plates were welded in a single pass, using different tapered tool pin profiles such as cylindrical tapered, hexagon tapered, pentagon tapered, square tapered and triangular $\mathrm{c}$ of $10^{\circ}$ and pin length of $5.7 \mathrm{~mm}$ (Fig. 1). The circumscribed circle diameter of the tool pin was kept the same for all different pins. Considering the weld quality on AA 5052-H32 aluminium plates and tool wear rate, a non-consumable tool made of H13 steel was selected ${ }^{26,27}$ to fabricate the joints. As prescribed by the design matrix totally 31 joints were fabricated in this investigation.

Tensile tests were carried out by UTM, DAK-UTB 9103 with $100 \mathrm{kN}$ capacities. The samples were prepared by EDM as per ASTM - E8 standard for the test ${ }^{28}$. Microhardness measurements were carried out by Vickers microhardness testing machine (make: Mitutoyo, Japan, and model: HM113) using $50 \mathrm{gf}$ load for $10 \mathrm{~s}$ holding time. For microstructure examination, specimens were cut perpendicular to the welding direction by EDM and then electropolished for metallographic analysis. Electron backscatter diffraction (EBSD) was carried out in the parent alloy and weld zones for EBSD band contrast/IPF images by an FEI Quanta FEG SEM equipped with TSL-OIM software. The tensile fractured surfaces were examined by scanning electron microscope (SEM, Jeol JSM - 6390LV/JED - 2300) at different magnifications to analyze the fracture features of the joints. 
Table 1. Chemical composition of Al 5052 H32 alloy

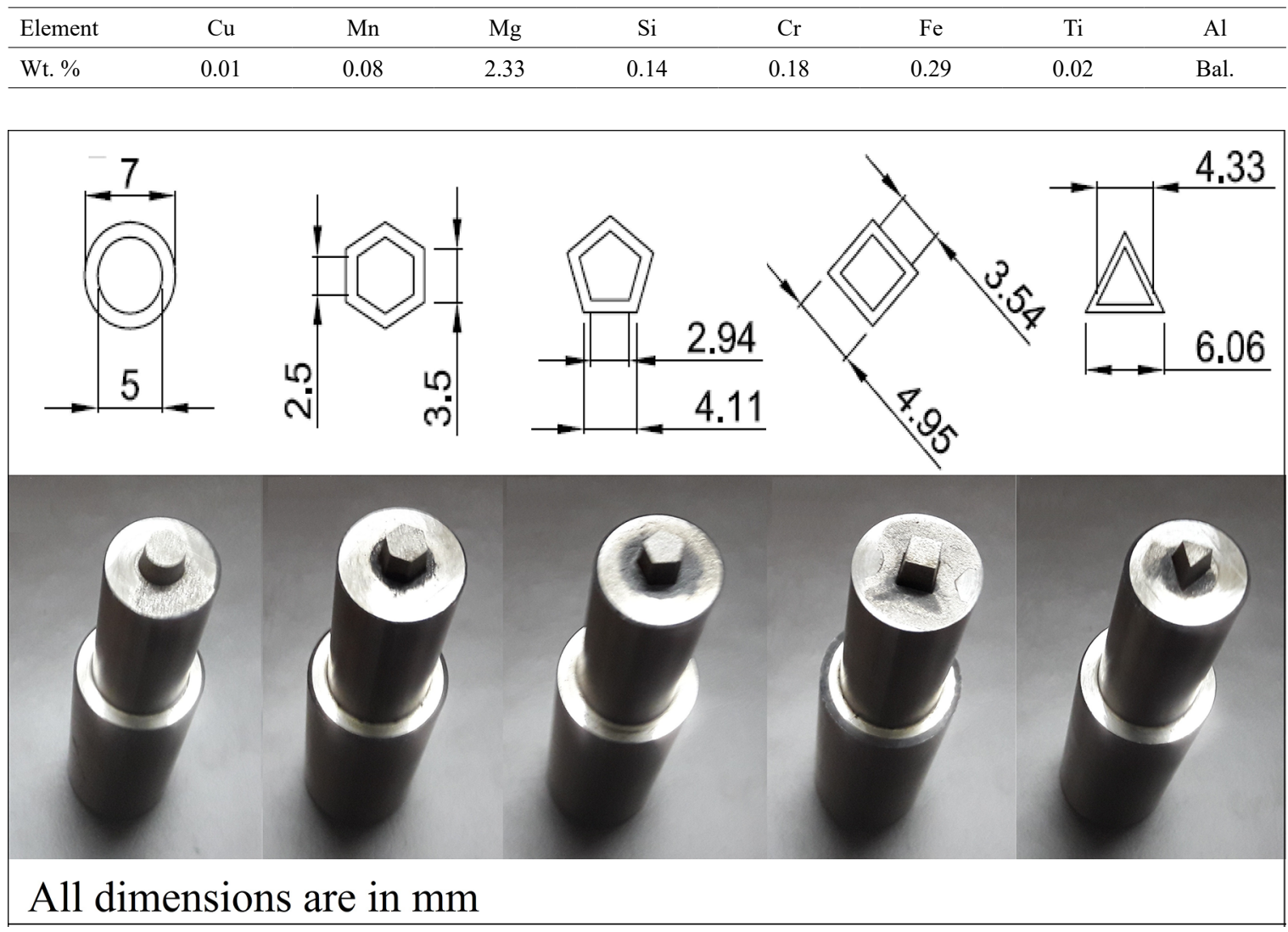

Figure 1. FSW tool pin profiles.

The significant factors that influence the joint properties and the working ranges of those factors of AA 5052-H32 aluminium alloy are presented in Table 2. Trial welds are carried out to fix the center point (middle level) and working ranges of all selected parameters. Four factors, five levels, and a central composite response surface method design matrix with 31 runs are used to design the experimental runs. Table 3 shows the experimental design matrix.

The upper limit and lower limit of the factors are coded as +2 and -2 , respectively. The intermediate values are calculated using the relationship,

$$
X_{i}=2\left[2 X-\left(X_{\max }+X_{\min }\right) / X_{\max }-X_{\min }\right]
$$

where $X_{i}$ is the required coded value of variable $X, X$ is any value of the variable from $X_{\min }$ to $X_{\max }, X_{\min }$ is the lowest level of the variable and $X_{\max }$ is the highest level of the variable.

Photograph of the tensile tested 32 specimens (a base metal and 31 joints) are displayed in Fig. 2. In the figure, advancing side and retreating side of the welded specimens are labeled as AS and RS, respectively, and the base metal is labeled as BM. The joints fabricated using tapered square pin profile tool with a rotational speed of $600 \mathrm{rpm}$, welding speed of $65 \mathrm{~mm} / \mathrm{min}$, and tilt angle of $1.5^{\circ}$ (run-30) exhibits maximum tensile strength compared to other joints. But decrease in tilt angle to $0.5^{\circ}$ (run-23) with other parameters fixed at the above levels exhibits minimum tensile strength compared to other joints. This shows that the tool tilt angle has a significant role in determining the tensile strength of the welded joint. The maximum efficiency determined from the experiment runs form on DOE is $93.51 \%$. The joint which exhibited maximum tensile strength (run-30) fractured at the heat affected zone on the retreating side of the welded joint. The heat-affected region is the weaker region where crack propagates in high strength welded joints. Good bonding at the stir zone due to optimum heat generation and strain rate at the stir zone, and less heat generation and material consolidation at the retreating side compared to the advancing side leads to the joint fracture at retreating side. The joint exhibits minimum tensile strength (run-23) fractured at the stir zone of the welded joint. This is due to poor bonding at the stir zone due to very low frictional heat generation.

Fig. 3 shows the SEM image of the fractured surface of the base metal sample and welded sample (run-30) with high tensile strength, subjected to the tensile test. The fractured surface of both samples consists of small dimples, indicating a decrease of plastic deformation level during the tensile test. Higher magnification of the fractured surface of both samples shows clearly a very dense grouping of very small 
Table 2. Significant factors and their levels

\begin{tabular}{lccccccc}
\hline \multirow{2}{*}{ Ser. No. } & Parameter & Unit & \multicolumn{5}{c}{ Levels } \\
\cline { 4 - 8 } & & & $(-2)$ & $(-1)$ & $(0)$ & $(+1)$ & $(+2)$ \\
\hline 1 & Tool pin profile (Tapered), P & - & Hexagon & Pentagon & Square & Cylindrical & Triangular \\
2 & Rotational speed, N & rpm & 400 & 500 & 600 & 700 & 800 \\
3 & Welding speed, S & mm/min & 45 & 55 & 65 & 75 & 85 \\
4 & Tool tilt angle, A & Degree & 0.5 & 1 & 1.5 & 2 & 2.5 \\
\hline
\end{tabular}

Table 3. Design matrix with experimental results

\begin{tabular}{|c|c|c|c|c|c|c|c|}
\hline \multirow{2}{*}{ Trial Run } & \multicolumn{4}{|c|}{ Factor } & \multirow{2}{*}{ UTS (MPa) } & \multirow{2}{*}{$\begin{array}{l}\text { Hardness } \\
(\mathrm{Hv})\end{array}$} & \multirow{2}{*}{$\begin{array}{c}\text { Weld } \\
\text { efficiency }(\%)\end{array}$} \\
\hline & $\mathrm{P}$ & $\mathrm{N}$ & $\mathrm{S}$ & $\mathrm{A}$ & & & \\
\hline 1 & -1 & -1 & -1 & -1 & 196.09 & 56.1 & 90.76 \\
\hline 2 & +1 & -1 & -1 & -1 & 184.97 & 52.6 & 85.61 \\
\hline 3 & -1 & +1 & -1 & -1 & 193.99 & 54.1 & 89.78 \\
\hline 4 & +1 & +1 & -1 & -1 & 184.27 & 52.1 & 85.29 \\
\hline 5 & -1 & -1 & +1 & -1 & 193.48 & 55.8 & 89.55 \\
\hline 6 & +1 & -1 & +1 & -1 & 179.48 & 52.2 & 83.07 \\
\hline 7 & -1 & +1 & +1 & -1 & 190.16 & 54.5 & 88.01 \\
\hline 8 & +1 & +1 & +1 & -1 & 175.69 & 52.0 & 81.32 \\
\hline 9 & -1 & -1 & -1 & +1 & 196.95 & 58.0 & 91.15 \\
\hline 10 & +1 & -1 & -1 & +1 & 194.34 & 58.4 & 89.95 \\
\hline 11 & -1 & +1 & -1 & +1 & 198.80 & 57.5 & 92.01 \\
\hline 12 & +1 & +1 & -1 & +1 & 196.84 & 58.9 & 91.10 \\
\hline 13 & -1 & -1 & +1 & +1 & 198.78 & 57.1 & 92.00 \\
\hline 14 & +1 & -1 & +1 & +1 & 195.39 & 57.2 & 90.43 \\
\hline 15 & -1 & +1 & +1 & +1 & 198.64 & 56.3 & 91.94 \\
\hline 16 & +1 & +1 & +1 & +1 & 196.62 & 56.6 & 91.00 \\
\hline 17 & -2 & 0 & 0 & 0 & 194.72 & 55.9 & 90.12 \\
\hline 18 & +2 & 0 & 0 & 0 & 182.56 & 52.5 & 84.49 \\
\hline 19 & 0 & -2 & 0 & 0 & 190.21 & 54.5 & 88.04 \\
\hline 20 & 0 & +2 & 0 & 0 & 191.48 & 54.6 & 88.62 \\
\hline 21 & 0 & 0 & -2 & 0 & 197.58 & 58.2 & 91.45 \\
\hline 22 & 0 & 0 & +2 & 0 & 191.81 & 57.7 & 88.78 \\
\hline 23 & 0 & 0 & 0 & -2 & 175.09 & 52.3 & 81.04 \\
\hline 24 & 0 & 0 & 0 & +2 & 196.79 & 59.8 & 91.08 \\
\hline 25 & 0 & 0 & 0 & 0 & 199.55 & 59.2 & 92.36 \\
\hline 26 & 0 & 0 & 0 & 0 & 200.32 & 59.0 & 92.71 \\
\hline 27 & 0 & 0 & 0 & 0 & 201.42 & 59.1 & 93.22 \\
\hline 28 & 0 & 0 & 0 & 0 & 200.03 & 59.5 & 92.58 \\
\hline 29 & 0 & 0 & 0 & 0 & 199.13 & 60.0 & 92.16 \\
\hline 30 & 0 & 0 & 0 & 0 & 202.04 & 58.9 & 93.51 \\
\hline 31 & 0 & 0 & 0 & 0 & 199.43 & 59.4 & 92.30 \\
\hline
\end{tabular}

dimples around large dimples, which reveals a good ductile mode of fracture. The study reveals that the ductility of the welded sample with high tensile strength is on a par with parent alloy.

\section{Macro and Microstructures}

Fig. 4 shows the optical macrograph of the cross-section perpendicular to the tool transverse direction of the welded specimen with high tensile strength. Defects such as voids, 


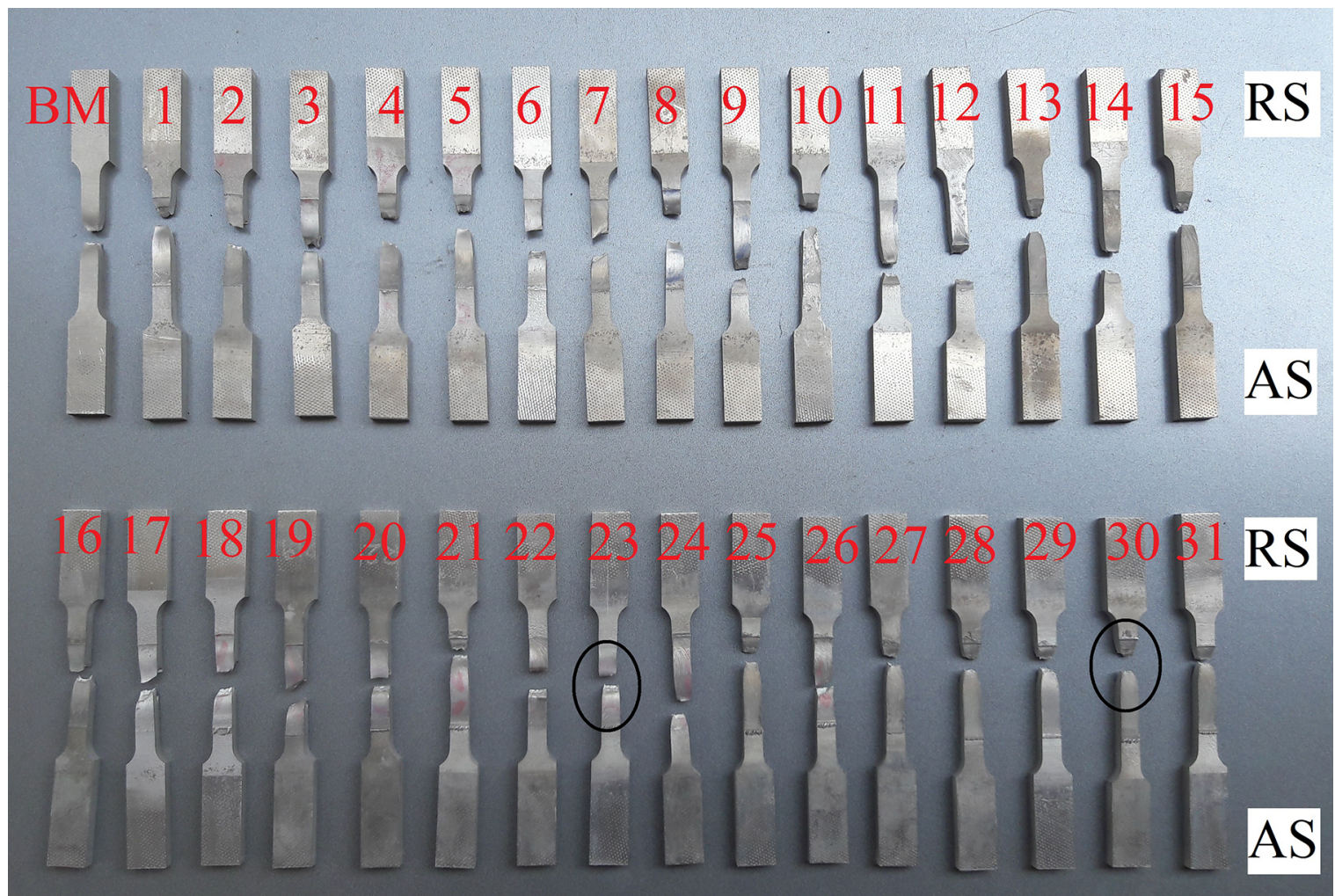

Figure 2. Tensile tested specimens.
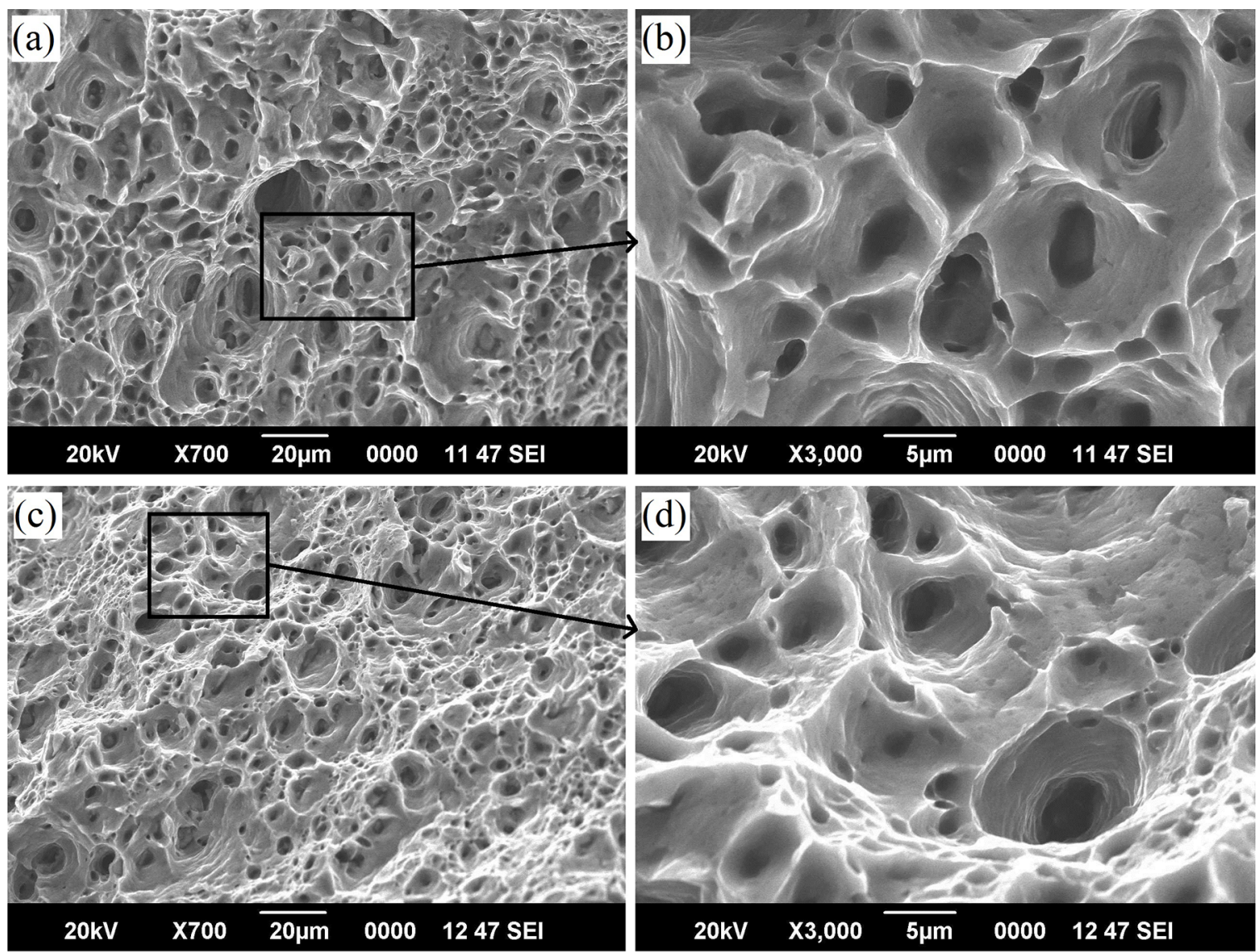

Figure 3. Fractured surface: (a) \& (b) base metal, (c) \& (d) FS welded sample with high tensile strength. 


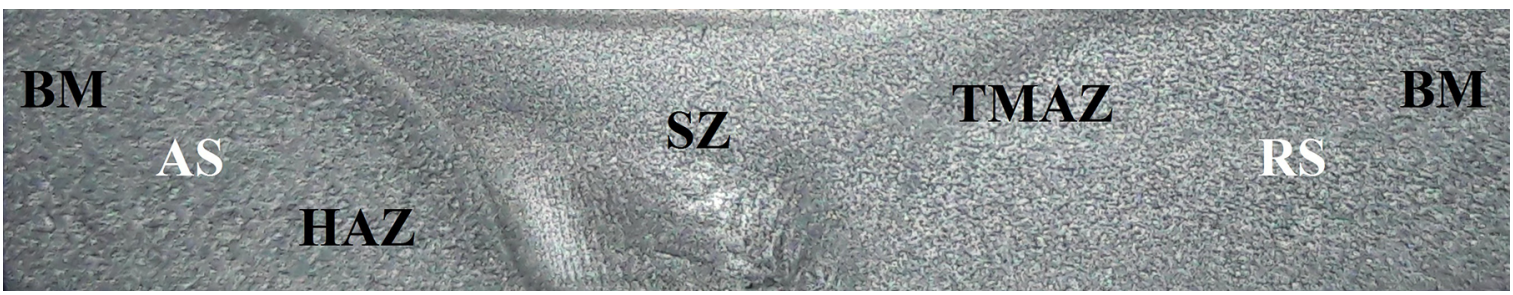

Figure 4. Cross sectional macrograph of the welded specimen with high tensile strength.

cracks, and unbonded zones are not observed in and around the stir zone. Base metal (BM) and different weld zones such as the heat hazard zone (HAZ), the thermo-mechanically affected zone (TMAZ), and the stir zone (SZ) are labeled in the macrograph. Fig. 5 illustrates the EBSD band contrast/IPF images of the base metal and different zones of the welded sample with high tensile strength. The grain structure of the base metal is not uniformed, elongated or non-equiaxed and found coarse, but the stir zone composed of very smaller grains. TMAZ has an elongated grain structure with an average grain size of $34.49 \mu \mathrm{m}$ owing to the strain during mechanical stirring. In the HAZ region, grains are found coarse and elongated with an average grain size of $57.23 \mu \mathrm{m}$ owing to the secondary recrystallization at the region, and together with the increased temperature might stimulate grain growth. The average grain size in the base metal is $48.82 \mu \mathrm{m}$ and grain size in stir zone of FSW joint is $6.9 \pm 3.59 \mu \mathrm{m}$. This suggests that the stir zone experienced plastic deformation at higher strain rates by the mechanical stirring action of the rotating probe of the tool during the FSW process. Distortion of the microstructure occurs at the BM is due to the cold working of aluminium alloy. Distorted grains lead to fragmentation and formation of refined and equiaxed grains at the stir zone. Restoration/refinement process taking place simultaneously with deformation is called dynamic recrystallization. Grain refinement occurs at the stir zone is as a result of dynamic recrystallization. During dynamic recrystallization, the low angle grain boundaries in the parent alloy get replaced by high angle grain boundaries in the stir zone due to the continuous rotation of the sub-grains (low angle grain boundaries). Absorption of dislocations by low angle boundaries increases the misorientation until the formation of high angle grain boundaries ${ }^{29,30}$. A higher fraction of high angle grain boundaries $\left(>15^{\circ}\right)$ was observed in the stir zone of FS welded joints compared to parent alloy as illustrated in Fig. 6. The stored energy is the driving force for recrystallization in cold hardened materials ${ }^{31}$.

\section{Response Surface Methodology}

The response functions such as ultimate tensile strength (UTS) in $\mathrm{MPa}$ and Hardness (H) in $\mathrm{Hv}$ of the joints are functions of the tool pin profile $(\mathrm{P})$, rotational speed $(\mathrm{N})$ in $\mathrm{rpm}$, welding speed (S) in $\mathrm{mm} / \mathrm{min}$, and tool tilt angle (A) in degree. It can be expressed as

$$
\begin{gathered}
U T S=f(P, N, S, A) \\
H=f(P, N, S, A)
\end{gathered}
$$

The mathematical model developed to predict grey relation grade (GRG) of FSW joints of the AA 5052-H32 aluminium alloy is given below:

$$
\begin{aligned}
& G R G=0.87206-0.04701 P-0.00425 N- \\
& 0.03675 S+0.11775 A-0.09701 P^{2}- \\
& 0.09443 N^{2}-0.0504 S^{2}-0.06898 A^{2}+ \\
& 0.01375 P N-0.00721 P S+0.03714 P A- \\
& 0.00779 N S+0.01551 N A-0.00323 S A
\end{aligned}
$$

\section{Analyze the Experimental Results Using the Grey Relational Grade and ANOVA.}

\subsection{Grey relational analysis (GRA)}

GRA is a decision-making technique introduced by Deng. In GRA, two types of data exist namely, known and unknown. The known and unknown data are designated as 'white' and 'black', respectively. During experimentation, in addition to these data, there may be some incomplete data. The incomplete data are together called the grey system. Ultimate tensile strength and hardness were considered in the study for maximization. The step by step GRA analysis is shown below.

- Normalize the experimental results of UTS and hardness.

- $\quad$ Perform the grey relational generating and calculate the grey relational coefficient.

- Compute the grey relational grade by averaging the grey relational coefficients.

- Analyze the experimental results using the grey relational grade and ANOVA.

- $\quad$ Select the optimal levels of process parameters.

- Verify the optimal process parameters through the confirmation tests. 

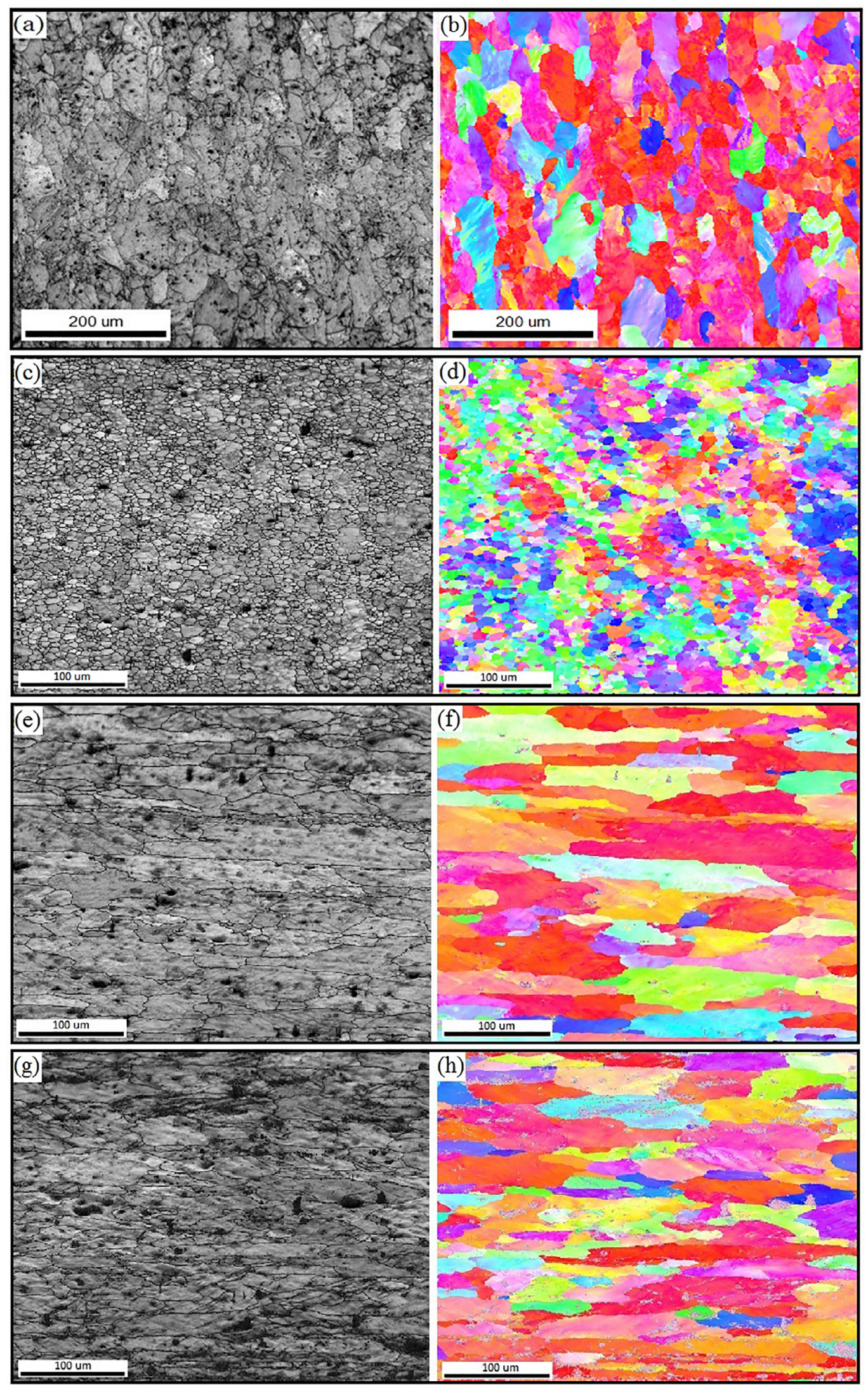

Figure 5. EBSD band contrast/IPF images: (a) \& (b) base metal, (c) \& (d) stir zone, (e) \& (f) HAZ, (g) \& (h) TMAZ of the FS welded sample with high tensile strength. 

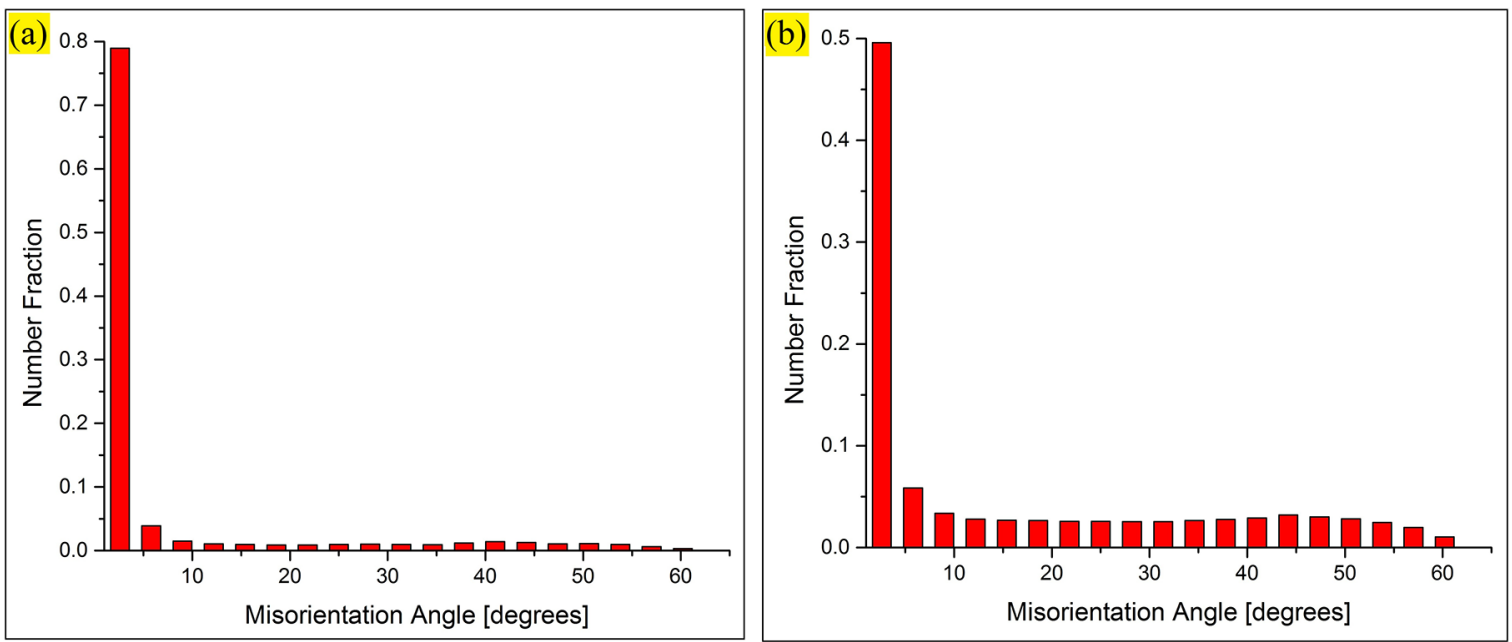

Figure 6. Frequency of grain boundary misorientation angles: (a) base metal, (b) stir zone of the FS welded joint.

The response data are normalized between 0 and 1 based on grey relation theory. "Larger the better" criteria is used to maximize the response since the quality of the welded joint is based on a higher value of ultimate tensile strength and hardness. The following equation is used for normalization:

$$
x_{i}^{*}(k)=\frac{x_{i}^{0}(k)-\min x_{i}^{0}(k)}{\max x_{i}^{0}(k)-\min x_{i}^{0}(k)}
$$

where $x_{i}^{*}(k)$ is the normalized value and $x_{i}^{0}(k)$ is the response value, $\min x_{i}^{0}(k)$ is the lowest response value and $\max x_{i}^{0}(k)$ is the highest response value. From data preprocessing, a grey relation coefficient is computed by the following equation.

$$
\xi_{i}(k)=\frac{\Delta_{\min }+\zeta \Delta_{\max }}{\Delta_{o i}(k)+\zeta \Delta_{\max }}
$$

where $\Delta_{o i}(k)$ is the deviation sequence, the difference of the reference sequence $x_{0}^{*}(k)$ and comparability sequence $x_{i}^{*}(k) . \zeta$ is distinguishing or identification coefficient and is assumed to be 0.5 since all the parameters are given equal preference. $\Delta_{\max }$ is the highest value of $\Delta_{o i}(k) ; \Delta_{\min }$ is the lowest value of $\Delta_{o i}(k)$. The overall evaluation of the multiple performance characteristics is based on the grey relational grade. The grey relational grades are computed by averaging the grey relational coefficient corresponding to each performance characteristic.

$$
\gamma_{i}=\frac{1}{n} \sum_{k=1}^{n} \xi_{i}(k)
$$

where $\gamma_{i}$ is the grey relational grade for the $\mathrm{i}^{\text {th }}$ experiment and $\mathrm{n}$ is the number of performance characteristics. The calculated normalized value, grey relational coefficient, grey relation grade and rank based on higher grey relation grade the better are tabulated in table 4 .

\subsection{Adequacy of the developed model}

The statistical result narrated in table 5 gives the $\mathrm{R}$-square value and adjusted R-square value of $99 \%$ and $98 \%$, respectively for the GRG, indicating a very high degree of match exists between the predicted model and experimental value. The adequacy of regression models was tested using the analysis of variance technique (ANOVA). The Table 6 reveals that the calculated value of F-ratio of the tested model is very higher than the tabulated value of F-ratio at 95\% confidence level indicates that models are accurate and there is no significant difference between the experimental value and the predicted model. Fig. 7 represents the residual plots, which indicates the perfect fitness of the developed empirical relationships. The histogram and observation order of the residual plot shows that the residual points are distributed on each side. Normal probability plot and versus fits of the residual plot shows that the developed regression model is accurate.

\section{Analysis of Response Plots.}

Fig. 8 depicts the main effect plot to analyze the quality of the FS-welded specimens. Effect of each input welding parameters on the quality of the weld is assessed graphically by the plot. Based on the main effect plot, the input parameters such as tool profile, rotational speed, and welding speed are found significant when they coming nearer to their center levels, whereas their lower and higher levels did not significantly affect the quality of the FS-welded specimens. But the tool tilt angle is found significant when it is in between center level and higher level. Also, within the range of values considered for modelling the input variables, the welding speed has a lower influence on the quality than the other variables, since the difference between the minimum and 
Table 4. Computational result of grey relation grade

\begin{tabular}{|c|c|c|c|c|c|c|c|c|}
\hline \multirow[b]{2}{*}{ Trial Run } & \multirow[b]{2}{*}{ UTS (MPa) } & \multirow{2}{*}{$\begin{array}{l}\text { Hardness } \\
(\mathrm{Hv})\end{array}$} & \multicolumn{2}{|c|}{ Normalized value } & \multicolumn{2}{|c|}{ Grey relational coefficient } & \multirow{2}{*}{$\begin{array}{c}\text { Grey } \\
\text { relational } \\
\text { grade }\end{array}$} & \multirow[b]{2}{*}{ Rank } \\
\hline & & & UTS & Hardness & UTS & Hardness & & \\
\hline 1 & 196.09 & 56.1 & 0.78 & 0.51 & 0.69 & 0.51 & 0.60 & 19 \\
\hline 2 & 184.97 & 52.6 & 0.37 & 0.08 & 0.44 & 0.35 & 0.40 & 26 \\
\hline 3 & 193.99 & 54.1 & 0.70 & 0.26 & 0.63 & 0.40 & 0.51 & 22 \\
\hline 4 & 184.27 & 52.1 & 0.34 & 0.01 & 0.43 & 0.34 & 0.38 & 27 \\
\hline 5 & 193.48 & 55.8 & 0.68 & 0.48 & 0.61 & 0.49 & 0.55 & 21 \\
\hline 6 & 179.48 & 52.2 & 0.16 & 0.03 & 0.37 & 0.34 & 0.36 & 29 \\
\hline 7 & 190.16 & 54.5 & 0.56 & 0.31 & 0.53 & 0.42 & 0.48 & 25 \\
\hline 8 & 175.69 & 52.0 & 0.02 & 0.00 & 0.34 & 0.33 & 0.34 & 31 \\
\hline 9 & 196.95 & 58.0 & 0.81 & 0.75 & 0.73 & 0.67 & 0.70 & 12 \\
\hline 10 & 194.34 & 58.4 & 0.71 & 0.80 & 0.64 & 0.71 & 0.68 & 14 \\
\hline 11 & 198.80 & 57.5 & 0.88 & 0.69 & 0.81 & 0.62 & 0.71 & 11 \\
\hline 12 & 196.84 & 58.9 & 0.81 & 0.86 & 0.72 & 0.78 & 0.75 & 9 \\
\hline 13 & 198.78 & 57.1 & 0.88 & 0.64 & 0.81 & 0.58 & 0.69 & 13 \\
\hline 14 & 195.39 & 57.2 & 0.75 & 0.65 & 0.67 & 0.59 & 0.63 & 16 \\
\hline 15 & 198.64 & 56.3 & 0.87 & 0.54 & 0.80 & 0.52 & 0.66 & 15 \\
\hline 16 & 196.62 & 56.6 & 0.80 & 0.58 & 0.71 & 0.54 & 0.63 & 17 \\
\hline 17 & 194.72 & 55.9 & 0.73 & 0.49 & 0.65 & 0.49 & 0.57 & 20 \\
\hline 18 & 182.56 & 52.5 & 0.28 & 0.06 & 0.41 & 0.35 & 0.38 & 28 \\
\hline 19 & 190.21 & 54.5 & 0.56 & 0.31 & 0.53 & 0.42 & 0.48 & 24 \\
\hline 20 & 191.48 & 54.6 & 0.61 & 0.33 & 0.56 & 0.43 & 0.49 & 23 \\
\hline 21 & 197.58 & 58.2 & 0.83 & 0.78 & 0.75 & 0.69 & 0.72 & 10 \\
\hline 22 & 191.81 & 57.7 & 0.62 & 0.71 & 0.57 & 0.63 & 0.60 & 18 \\
\hline 23 & 175.09 & 52.3 & 0.00 & 0.04 & 0.33 & 0.34 & 0.34 & 30 \\
\hline 24 & 196.79 & 59.8 & 0.80 & 0.98 & 0.72 & 0.95 & 0.84 & 8 \\
\hline 25 & 199.55 & 59.2 & 0.91 & 0.90 & 0.84 & 0.83 & 0.84 & 7 \\
\hline 26 & 200.32 & 59.0 & 0.94 & 0.88 & 0.89 & 0.80 & 0.84 & 6 \\
\hline 27 & 201.42 & 59.1 & 0.98 & 0.89 & 0.96 & 0.82 & 0.89 & 3 \\
\hline 28 & 200.03 & 59.5 & 0.93 & 0.94 & 0.87 & 0.89 & 0.88 & 4 \\
\hline 29 & 199.13 & 60.0 & 0.89 & 1.00 & 0.82 & 1.00 & 0.91 & 1 \\
\hline 30 & 202.04 & 58.9 & 1.00 & 0.86 & 1.00 & 0.78 & 0.89 & 2 \\
\hline 31 & 199.43 & 59.4 & 0.90 & 0.93 & 0.84 & 0.87 & 0.85 & 5 \\
\hline
\end{tabular}

Table 5. Statistical results

\begin{tabular}{cccc}
\hline Response & R-Square & $\begin{array}{c}\text { Adjusted } \\
\text { R-Square }\end{array}$ & $\begin{array}{c}\text { Standard } \\
\text { error }\end{array}$ \\
\hline GRG & 0.99 & 0.98 & 0.02 \\
\hline
\end{tabular}

maximum values of GRG are lower. The joint fabricated with the square pin has the highest GRG value, reveal that among the various pin used in the experiment square pin produce high quality welded joint.

Table 6. ANOVA results

\begin{tabular}{lcccccc}
\hline \multirow{2}{*}{ Response } & \multirow{2}{*}{ Source } & Sum of squares & Degrees of freedom & Mean square & \multicolumn{2}{c}{ F-ratio } \\
\cline { 5 - 7 } & & & & & (calculated) & (tabulated) \\
\multirow{2}{*}{ GRG } & Regression & 1.005 & 14 & 0.072 & 124.3 & 2.37 \\
& Residual & 0.009 & 16 & 0.0005 & - & - \\
\hline
\end{tabular}


Fig. 9 represents 3D surface plots for the GRG value obtained from the regression model. The maximum GRG value obtained is exhibited by the apex of the response surfaces. The value of GRG towards ' 1 ' represents a high quality of the welded joint in terms of both strength and hardness. Fig. 10 shows the contour plots and it is easier to understand the interaction effects of the input parameters by examining the contour plots. Fig. 10(a) exhibits an almost circular contour, which suggests independence of factor effects, namely tool pin profile and the rotational speed for weld quality at constant center points of $65 \mathrm{~mm} / \mathrm{min}$ welding speed and $1.5^{\circ}$ tool tilt angle. Fig. 10(b) shows that the change in the tool pin profile is more sensitive to the change in weld quality than the change in welding speed at constant center points of $600 \mathrm{rpm}$ rotational speed and $1.5^{0}$ tool tilt angle. Fig. 10(c) shows that the change in tool pin profile is slightly more sensitive to the change in weld quality than the change in tool tilt angle at constant center points of $600 \mathrm{rpm}$ rotational speed and $65 \mathrm{~mm} / \mathrm{min}$ welding speed. Fig. 10(d) shows that the change in rotational speed is more sensitive to the change in weld quality than the change in welding speed at constant center points of tapered square tool pin profile and $1.5^{\circ}$ tool tilt angle. Fig. 10(e) shows that the change in the rotational speed is slightly more sensitive to the change in weld quality than the change in tool tilt angle at constant center points of tapered square tool pin profile and $65 \mathrm{~mm} / \mathrm{min}$ welding speed. Fig. 10(f) exhibits a circular contour, which suggests independence of factor

\section{Residual Plots for GRG}
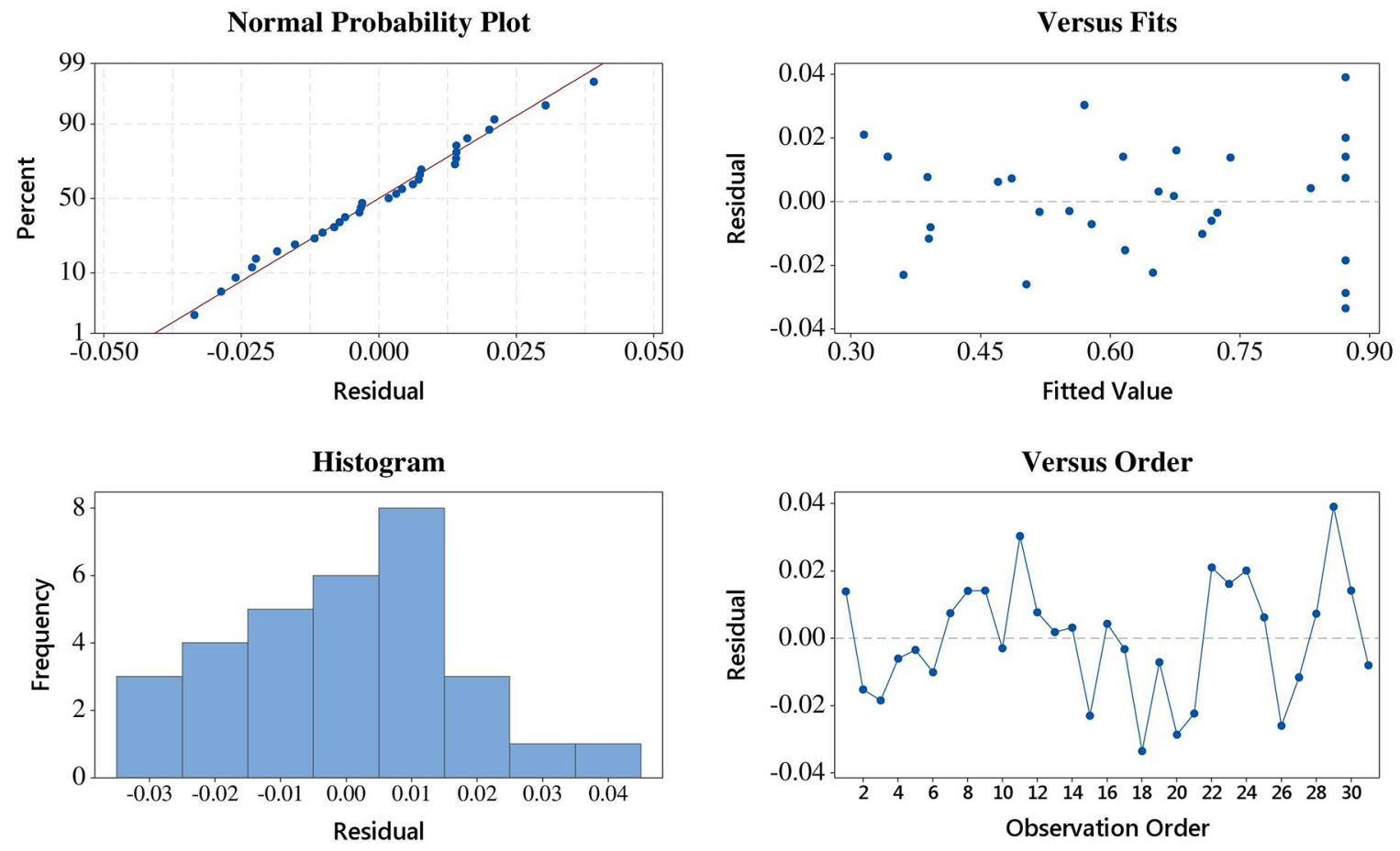

Figure 7. Residual plots for GRG.

\section{Main Effects Plot for GRG}

Fitted Means

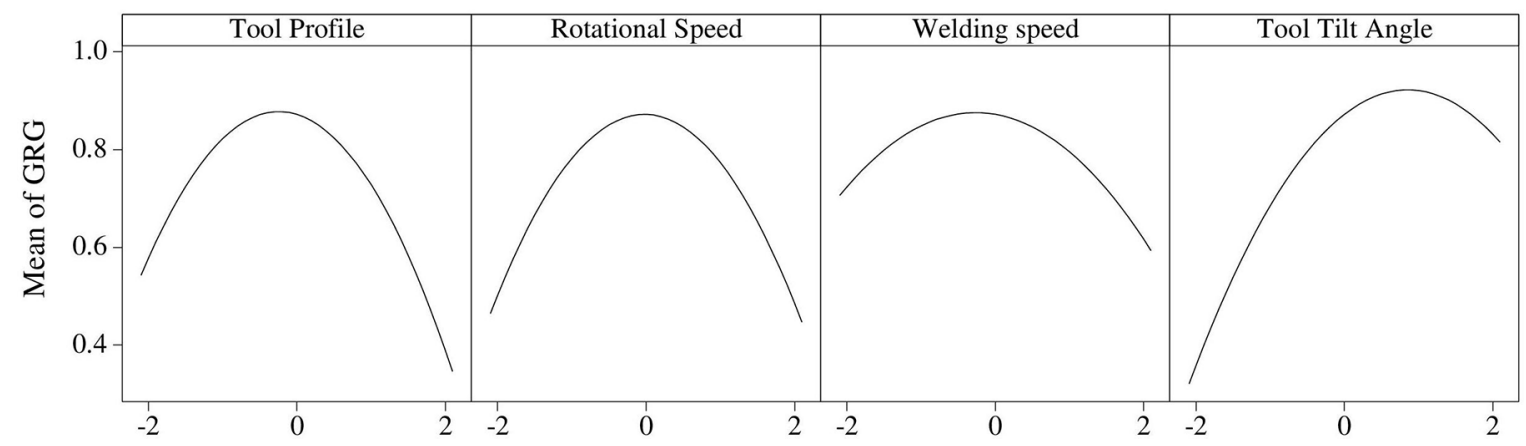

Figure 8. Main effects plot of input parameters vs. GRG. 


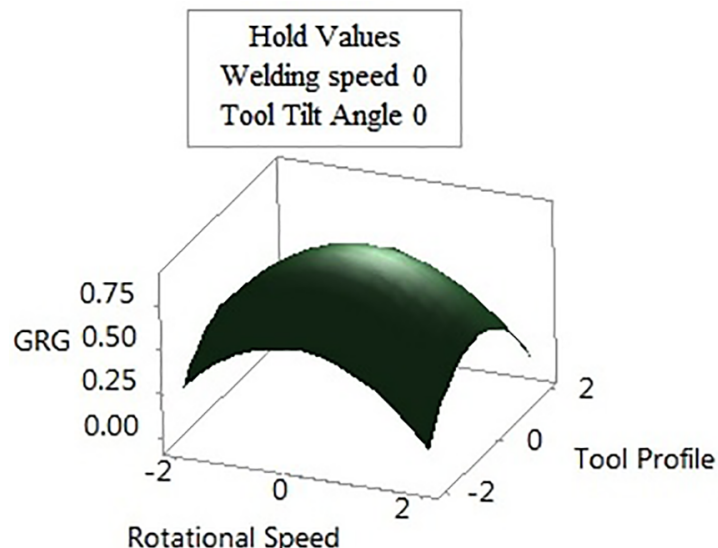

(a) GRG vs Tool Profile, Rotational Speed

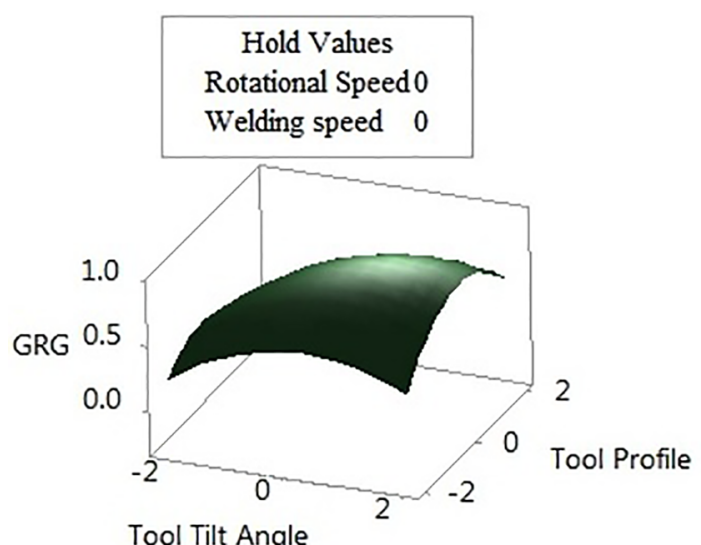

(c) GRG vs Tool Profile, Tool Tilt Angle

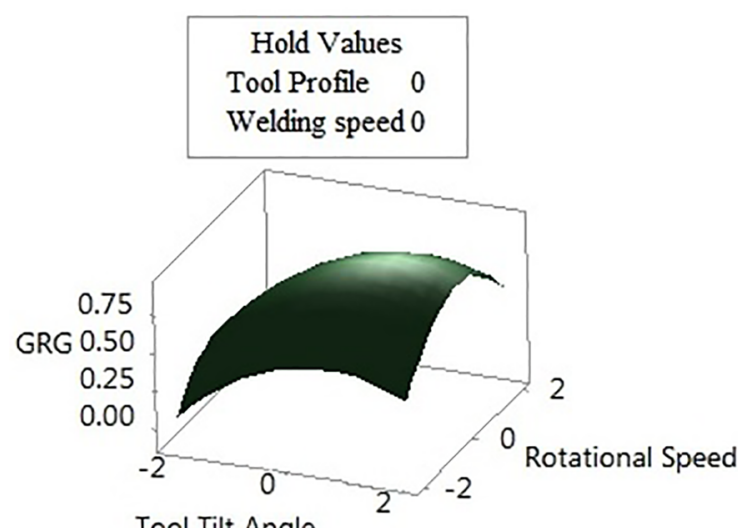

(e) GRG vs Rotational Speed, Tool Tilt Angle

Figure 9. Surface plots.

effects, namely welding speed and tool tilt angle for weld quality at constant center points of tapered square tool pin profile and $600 \mathrm{rpm}$ rotational speed. It is observed from the figures that, in all the conditions for quality weld the

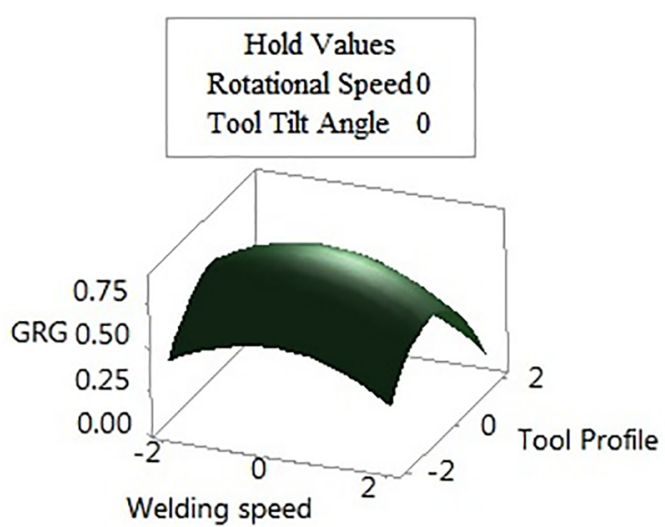

(b) GRG vs Tool Profile, Welding Speed

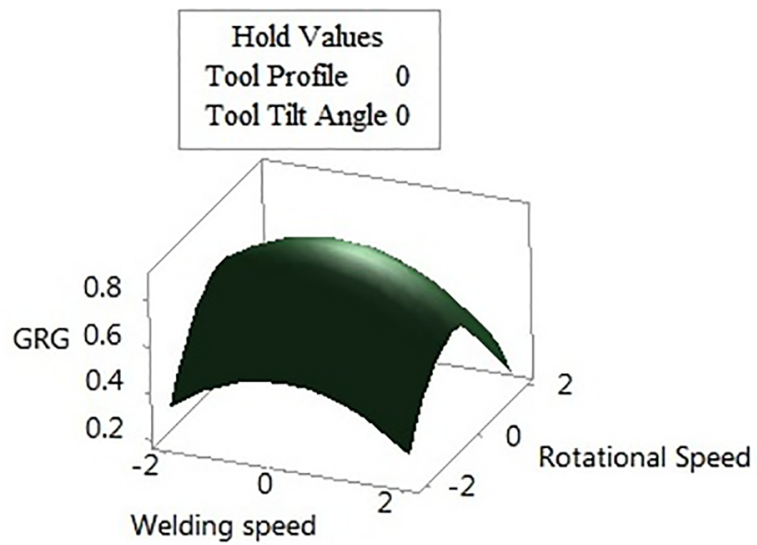

(d) GRG vs Rotational speed, Welding speed

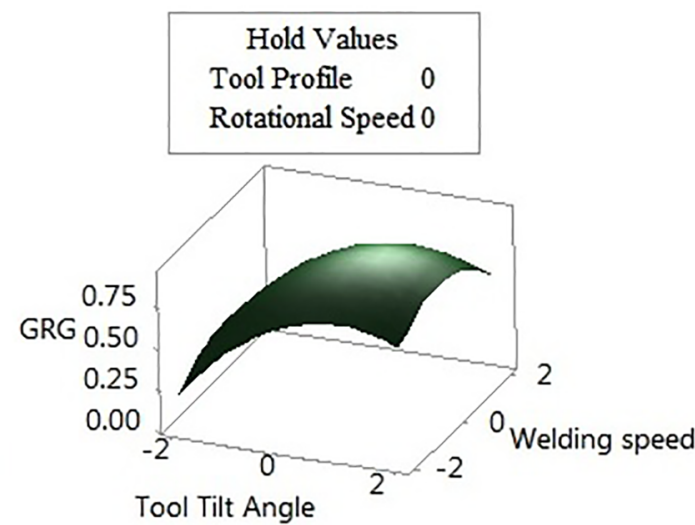

(f) GRG vs Welding Speed, Tool Tilt Angle

rotational speed is found at the center point of $600 \mathrm{rpm}$. The tool rotational speed has no significant interaction effect on the quality of the joint in the range considered for modelling $(400-800 \mathrm{rpm})$ 


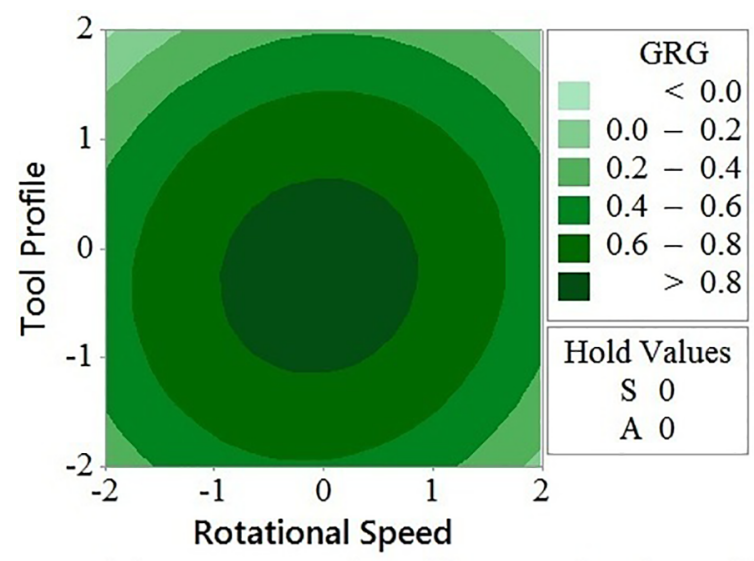

(a) GRG vs Tool Profile, Rotational speed

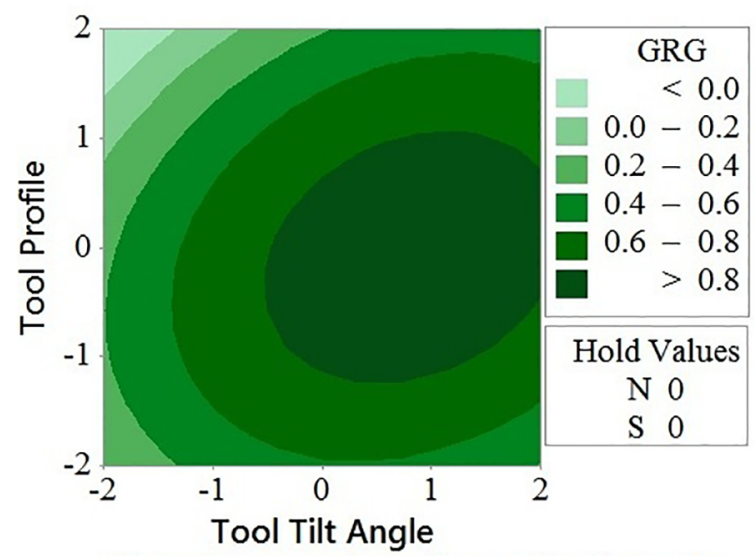

(c) GRG vs Tool Profile, Tool Tilt Angle

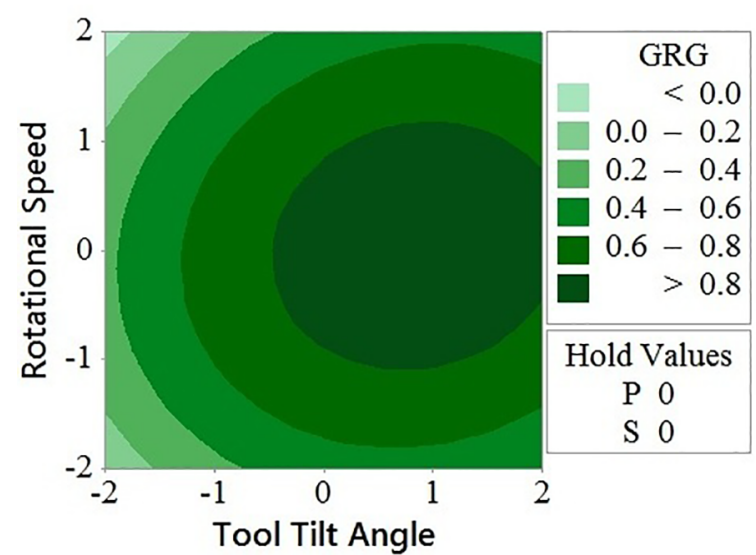

(e) GRG vs Rotational Speed, Tool Tilt Angle

Figure 10. Contour plots.

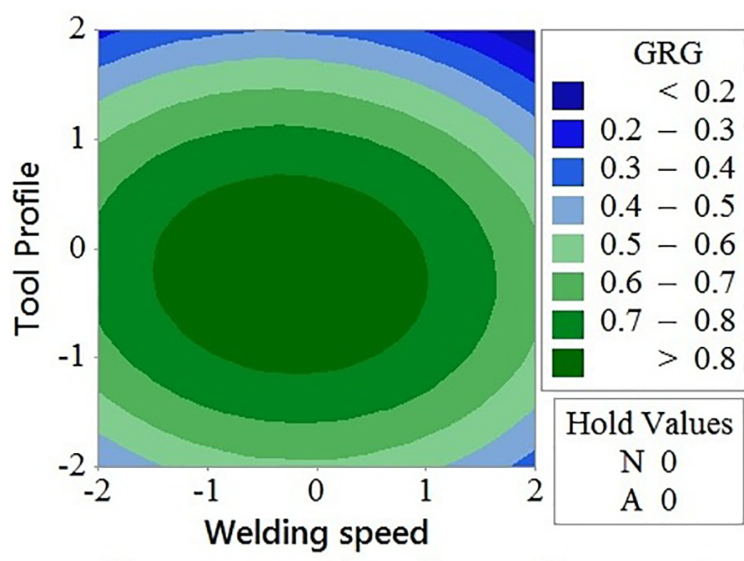

(b) GRG vs Tool Profile, Welding speed

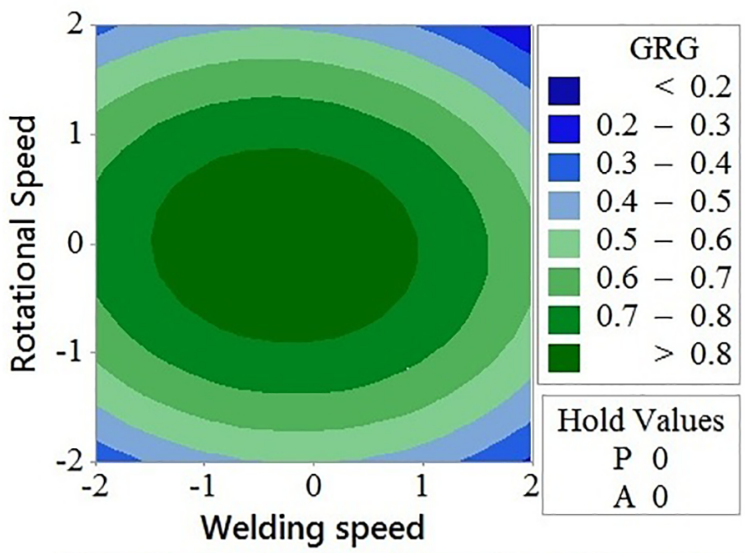

(d) GRG vs Rotational Speed, Welding speed

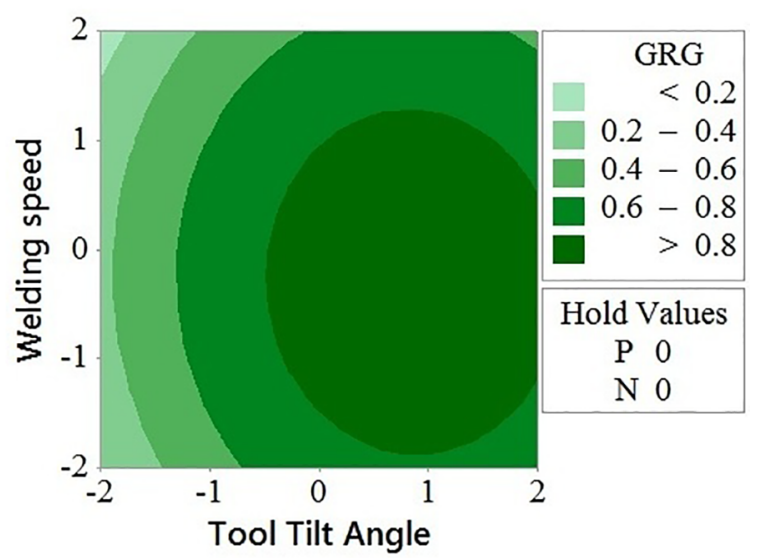

(f) GRG vs Welding Speed, Tool Tilt Angle

Table 7. Confirmation of experiment

\begin{tabular}{|c|c|c|c|c|c|c|c|}
\hline \multicolumn{4}{|c|}{ Optimized FSW parameters } & \multicolumn{4}{|c|}{ Response } \\
\hline \multirow[b]{2}{*}{ Pin profile } & \multirow{2}{*}{$\begin{array}{c}\text { Rotational } \\
\text { speed }\end{array}$} & \multirow{2}{*}{$\begin{array}{l}\text { Welding } \\
\text { speed }\end{array}$} & \multirow{2}{*}{$\begin{array}{l}\text { Tool Tilt } \\
\text { angle }\end{array}$} & \multicolumn{2}{|c|}{ Predicted } & \multicolumn{2}{|c|}{ Experimental } \\
\hline & & & & $\begin{array}{l}\text { UTS } \\
\text { (MPa) }\end{array}$ & $\begin{array}{c}\text { Hardness } \\
\text { (Hv) }\end{array}$ & $\begin{array}{c}\text { UTS } \\
\text { (MPa) }\end{array}$ & $\begin{array}{c}\text { Hardness } \\
\text { (Hv) }\end{array}$ \\
\hline $\begin{array}{l}\text { Tapered } \\
\text { square pin }\end{array}$ & $600 \mathrm{rpm}$ & $60 \mathrm{~mm} / \mathrm{min}$ & $1.9^{0}$ & 202.04 & 59.7 & 202.25 & 59.4 \\
\hline \multicolumn{4}{|c|}{ Grey relation grade (GRG) } & \multicolumn{2}{|c|}{0.97} & \multicolumn{2}{|c|}{0.94} \\
\hline \multicolumn{8}{|c|}{$\%$ Error in $\mathrm{GRG}=\{($ Experimental value - Predicted value $) /$ Predicted value $\} \times 100=-3 \%$} \\
\hline
\end{tabular}




\section{Optimization of Input Parameters and Confirmation by Experiments}

The optimal welding process parameters to maximize GRG were found out via Excel Solver tool. The regression equation obtained from mathematical modelling is used as the objective function. Constraints are used in the function to limit the values of the input factors. The optimum values of input factors for the predicted GRG value of 0.97 are rotational speed of $600 \mathrm{rpm}$, traverse speed of $60 \mathrm{~mm} / \mathrm{min}$, tool tilt angle of 1.9, and tapered square tool pin profile. Furthermore, a confirmation by the experiment was carried out to validate the predicted responses and the results are validated. Table 7 shows the confirmation of the result by experiments.

\section{Conclusion}

The multi-objective optimization using RSM and GRA determined the optimal levels of process parameters for the friction stir welded AA 5052-H32 aluminium alloy. In the present study, the quality of the weld is measured in terms of ultimate tensile strength and hardness of the joint.

The findings of the investigation can be summarized as follows:

1. The regression model was developed to estimate the response of the friction stir welded AA 5052-H32 aluminium alloy. The ANOVA analysis showed that the developed model can be effectively used to predict the response of the joints at $95 \%$ confidence level.

2. The effects of input welding parameters on the quality of the friction stir welded joints were presented and interpreted. The result shows that the tapered square tool pin profile can produce higher quality friction stir welded joints. The tool tilt angle has a major role in determining the quality of the welded joint. The better consolidation of the material under shoulder due to the increase in tool tilt angle increased the weld quality.

3. A defect-free weld is observed from macro and microstructural examination. The microstructure shows that grain refinement occurred at the stir zone as a result of dynamic recrystallization.

4. The quality of the weld increased with the increase of tool rotational speed, welding speed, and tool tilt angle and reached up to a maximum value, and then decreased.

5. Surface plots and contour plots were used to discuss the interaction of input welding parameters on weld quality.

6. The optimal values of input parameters to maximize quality in terms of both strength and hardness are as follows:
a. Pin profile - Tapered square (level: 0 )
b. Rotational speed - $600 \mathrm{rpm}$ (level: 0$)$
c. Welding speed - $60 \mathrm{~mm} / \mathrm{min}$ (level: -0.5 )
d. Tool tilt angle $-1.9^{0}$ (level: 0.8 )

7. The conformability of the predicted results indicates that the mathematical model and RSM based GRA are capable and sufficient for studying friction stir welded AA $5052 \mathrm{H} 32$ aluminum alloys. The maximum efficiency that resulted from the experiment (using the optimum value of input parameter) is $93.61 \%$.

\section{Acknowledgements}

Authors are grateful to Indian Institute of Technology Bombay (IIT-B) and Cochin University of Science and Technology (CUSAT) in Cochin, India for extending the facilities to carry out the SEM investigations.

\section{References}

1. Grimm A, Schulze S, Silva A, Göbel G, Standfuss J, Brenner B, et al. Friction Stir welding of Light Metals for Industrial Applications. Materialstoday: Proceedings. 2015;2(Suppl. 1) S:169-S178.

2. Mishra RS, Ma ZY. Friction sir welding and processing. Material Science and Engineering: R: Reports. 2005;50(1-2):1-78.

3. Shanavas S, Dhas JER. Modeling and Analysis of Friction Stir Welding and Underwater Friction Stir Welding of Aluminium Alloy: A Review. Applied Mechanics and Materials. 2017;867:127133.

4. Bhowmik A, Mishra D. A Comprehensive Study of an Aluminum Alloy AL-5052. Advance Physics Letter. 2016;3(1):20-22.

5. Gudić S, Vrsalović L, Kliškić M, Jerković I, Radonić A, Zekić M. Corrosion Inhibition of AA 5052 Aluminium Alloy in $\mathrm{NaCl}$ Solution by Different Types of Honey. International Journal of Electrochemical Science. 2016;11:998-1011.

6. Bayazid SM, Farhangi H, Ghahramani A. Effect of Pin Profile on Defects of Friction Stir Welded 7075 Aluminum Alloy. Procedia Materials Science. 2015;11:12-16.

7. Ugender S, Kumar A, Reddy AS. Experimental Investigation of Tool Geometry on Mechanical Properties of Friction Stir Welding of AA 2014 Aluminium Alloy. Procedia Materials Science. 2014;5:824-831.

8. Prasanna P, Penchalayya C, Rao DA. Effect of tool pin profiles and heat treatment process in the friction stir welding of AA 6061 aluminium alloy. American Journal of Engineering Research. 2013;2(1):7-15.

9. Venkateswarlu D, Mandal NR, Mahapatra MM, Harsh SP. Tool Design Effects for FSW of AA7039. Welding Journal. 2013;92:41-47.

10. Elangovan K, Balasubramanian V. Influence of tool pin profile and welding speed on the formation of friction stir processing zone in AA2219 aluminium alloy. Journal of Materials Processing Technology. 2008;200(1-3):163-175. 
11. Moshwan R, Yusof F, Hassan MA, Rahmat SM. Effect of tool rotational speed on force generation, microstructure and mechanical properties of friction stir welded Al-Mg-CrMn (AA 5052-O) alloy. Materials and Design (1980-2015). 2015;66(Pt A):118-128.

12. Kwon YJ, Shim SB, Park DH. Friction stir welding of 5052 aluminum alloy plates. Transactions of Nonferrous Metals of China. 2009;19(Suppl. 1):s23-s27.

13. Tufaro LN, Manzoni I, Svoboda HG. Effect of Heat Input on AA5052 Friction Stir Welds Characteristics. Procedia Materials Science. 2015;8:914-923.

14. Ramachandran KK, Murugan N, Kumar SS. Friction Stir Welding of Aluminum Alloy AA5052 and HSLA Steel. Welding Journal. 2015;94(9):291-300.

15. Shanavas S, Dhas JER. Weldability of AA $5052 \mathrm{H} 32$ aluminium alloy by TIG welding and FSW process - A comparative study. IOP Conference Series: Materials Science and Engineering. 2017;247:012016

16. Montgomery DC. Design and Analysis of Experiments. New York: Wiley; 2012.

17. Rajakumar S, Balasubramanian V. Establishing relationships between mechanical properties of aluminium alloys and optimised friction stir welding process parameters. Materials \& Design. 2012;40:17-35.

18. Palanivel R, Mathews PK, Murugan N. Development of mathematical model to predict the mechanical properties of friction stir welded AA6351 aluminum alloy. Journal of Engineering Science and Technology Review. 2011;4(1):2531 .

19. Elatharasan G, Senthil Kumar VS. An Experimental Analysis and Optimization of process Parameter on Friction Stir Welding of AA 6061-T6 Aluminium Alloy using RSM. Procedia Engineering. 2013;64:1227-1234.

20. Kadaganchi R, Gankidi MR, Gokhale H. Optimization of process parameters of aluminum alloy AA 2014-T6 friction stir welds by response surface methodology. Defence Technology. 2015;11(3):209-219.
21. Shanavas S, Dhas JER. Parametric optimization of friction stir welding parameters of marine grade aluminium alloy using response surface methodology. Transactions of Nonferrous Metals Society of China. 2017;27:2334-2344.

22. Kesharwani RK, Panda SK, Pal SK. Multi Objective Optimization of Friction Stir Welding Parameters for Joining of Two Dissimilar Thin Aluminum Sheets. Procedia Materials Science. 2014;6:178187.

23. Kundu J, Singh H. Friction stir welding of AA5083 aluminium alloy: Multi-response optimization using Taguchi-based grey relational analysis. Advances in Mechanical Engineering. 2016;8(11). DOI: $10.1177 / 1687814016679277$

24. Sahu PK, Pal S. Multi-response optimization of process parameters in friction stir welded AM20 magnesium alloy by Taguchi grey relational analysis. Journal of Magnesium and Alloys. 2015;3(1):3646.

25. Vijayan D, Rao VS. Friction Stir Welding of Age-Hardenable Aluminum Alloys: A Parametric Approach Using RSM Based GRA Coupled With PCA. Journal of The Institution of Engineers (India): Series C. 2014;95(2):127-141.

26. Rai R, De A, Bhadeshia HKDH, DebRoy T. Review: friction stir welding tools. Science and Technology of Welding and Joining. 2011;16(4):325-342.

27. Zhang Z, Wu Q, Zhang HW. Prediction of fatigue life of welding tool in friction stir welding of AA6061-T6. International Journal of Advanced Manufacturing Technology. 2016;8(9-12):3407-3415.

28. ASTM International. ASTM E8/E8M-09-Standard Test Methods for Tension Testing of Metallic Materials. West Conshohocken: ASTM International; 2010.

29. McNelley TR, Swaminathan S, Su JQ. Recrystallization mechanisms during friction stir welding/processing of aluminum alloys. Scripta Materialia. 2008;58(5):349-354.

30. Prangnell PB, Heason CP. Grain structure formation during friction stir welding observed by the 'stop action technique'. Acta Materialia. 2005;53(11):3179-3192.

31. Threadgill PL, Leonard AJ, Shercliff HR, Withers PJ. Friction stir welding of aluminium alloys. International Materials Reviews. 2013;54(2):49-93. 